\title{
fathers' involvement in early childhood education in indonesia
}

\author{
Fatima Rahmah ${ }^{1}$ \\ ${ }^{1}$ Faculty of Education, Monash University, Melbourne, Australia
}

\begin{abstract}
This study is explored the importance and the challenge of fathers' engagement in early years education in Indonesia. Previous research highlight that the fathers' involvement in children education could give positive feedback for both the father and the children. Participation of fathers in various children activities can promote fathers' awareness about their values towards their children. In Indonesia, the father presence at school remains invisible compared to the mother. Further, this exploration also found that the role of educator at school became one of an important thing to engage fathers' participation in their children education. Initiation of inviting fathers in children education needs to be started from the educators and teachers at schools. It is worth to consider for the school as an institution to learn how to engage fathers' participation in their children education in school-based and home-based activities. The study found that father with young children in Indonesia has a positive attitude towards their children's education. The domination of female presence in a children education setting is limiting fathers to participate in child education. Also, socio-culture, tradition, time limitation due to working hours, father's income, and education background of father affect fathers' involvement in child education.
\end{abstract}

Keywords: Children education, early childhood education, fathers' involvement, Indonesia

\section{Introduction, background, and significance}

Indonesia is a populous country that has a large population. It is also known as a multicultural country with many ethnic groups in society. As a multicultural country with different values and norms, Indonesia is a patriarchal family where fathers became a pillar for the families and are responsible for providing families needed. Moreover, as a leader in the family, fathers have more power to be a decision-maker than mothers. This condition is similar in Jordan, where the cultural and religious identities are embedded in Jordanian society (Ihmeideh, 2014). Ihmeideh (2014) explains that in the Jordanian society context, the family is "centred on the patriarchal extended family" (p.1049). It means that in Jordan, they live in a big family and fathers have a role to be responsible for the family's condition and as the centre of the family (Ihmeideh, 2014).

According to Ihmeideh (2014) study, he stated that among Jordanian, a father has significant power and authority over everything in their family. In the context of taking care of children in Jordanian society, the primary responsibility relies on mothers' role while fathers are going to be the one who is provide the family. This situation also found in Indonesia, which is the society expects that caregiving as mothers' responsibility. State of World Fathers (SOWF) Country 
Report: Indonesia (2015) shows that household work and taking care of children is considered as a female's job. The ManCare+ program was developed as an initiated project by SOWF in 2012, which is men care campaign to engage men in paternal activities, caregiving, child health and sexual reproductive health in Indonesia. SOWF (2015) reported that image of men in Indonesia was coloured by various factors such as culture, norm, religion, tradition, and also modern media which promote the concept of masculinity, while father as men are responsible for their family.

Yulindrasari and McGregor (2011) explored how modern media, which is parenting magazine, promote the value of fatherhood and motherhood in Indonesia. Yulindrasari and McGregor (2011) stated that fatherhood and motherhood views in Indonesia are determined by kodrat. Munir (1999, as cited in Yulindrasari \& McGregor, 2011) define kodrat as "inherent qualities of God's creature", which is formed from the Arabic word (p.607). By the time, kodrat has been rooted in the social norm and developed the character of men and women should behave in Indonesia society. Alongside with the study, Mathwasa and Okeke (2016b) also stated that many people think that it is natural for women to caring young children and concern to early childhood development while the majority thinks that men are not suitable for that.

Further, reflecting on the author experience during assisting a class in a local kindergarten in Indonesia, there were only a few fathers are engaged in their children education. The phenomenon was pictured in a condition when the kindergarten held a school-parent meeting program, as an annual program to invite parents and socialise the school program for the year ahead. The school-parent meeting program was targeted for both the mother and the father as parents and was held on Saturday. However, on the day of the event, the majority who attend are mothers, only a few fathers who are participating in that event, even though the event was held on the weekdays.

Goldman (2005) as cited in Mathwasa and Okeke (2016a) define that father's involvement as a father who has a relationship with his child and at the same time could be described as being sensitive, affectionate, warm, nurturing and encouraging, close, friendly, supportive, intimate, comforting and accepting. Relationship between children and father could be expressed by various activities, either in direct and indirect activities, such as reading children before bed and playing together. This paper aims to investigate the importance and challenge of fathers' participation in their children education in Indonesia.

\section{Research Method}

This is an in-depth literature review exploring the importance and the challenge of participation of fathers in their children education in Indonesia. This literature review paper is utilising the previous research related to the fathers' participation in early years education and its application in Indonesia context. The author initially conceptualises the fathers' involvement in early childhood education and narrowing the research question, which is pictured from the phenomenon of fathers' involvement in children education in Indonesia. Further, the author provides the discussion of the research questions and provides some implication for future practice. 


\section{Discussion}

\subsection{Fathers' participation in childhood development and education in the global and Indonesia context}

Children are learning from their surroundings. This could be described by the social learning theory while people are learnt through socialisation with their surrounding by interacting and observing other people (Mathwasa \& Okeke, 2016b). Bandura (1999) argue that people and their environment have mutual interaction with each other (Mathwasa \& Okeke, 2016b). Epstein (2000) as cited in Mathwasa and Okeke (2016) stated there are "three major sources" which determine children learning which are the family, community, and the school" (p. 230). In other words, children development is a result of their interaction throughout their surroundings, including their interaction with fathers, mothers, siblings, friends, and teachers.

Fathers' involvement could be defined as an interaction between fathers and their children, which is shown affection and availability of their presence around their children (Palm \& Fagan, 2008). Furthermore, Palm and Fagan (2008) define fathers' involvement in early childhood program as a direct and indirect connection that fathers have, including "selecting programs, participating in program-related activities, assuming responsibility for children's health and wellbeing in the program, and supporting joint program and family goals" (p.746). The following are specific activities which express fathers' participation with their children include: building relationship with teachers, volunteering in the classroom activities, participate in the family programs, attending in parenting education, home visits and program policy development (Palm \& Fagan, 2008).

In Western countries, there is a program which is inviting father to participate in school activities. For example, in the United States, there is Head Start (HS)/Early Head Start (EHS) program which engages fathers at school to participate in their children activities in early childhood education context (Fagan, Iglesias, \& Kaufman, 2016; Turbiville \& Marquis, 2001). Turbiville and Marquis (2001) explain that Head Start programs are a national program in the USA, which is funded by federal to serve young children from 3 to 5 years old and their families. For instance, Head Start programs are offer "Daddy and Me" program which promote activities between fathers and children at school (Turbiville \& Marquis, 2001). Furthermore, Zigler and Styfco (1995) described Head Start, as the program to increase young children's development with involving parents to participate in their children's education (Fagan et al., 2016). Most of this program is designed to invite fathers to join the school activities as a volunteer. For instance, there is a program called "Daddy and Me", where the fathers are asked to volunteer and explain their job to the children at school (Palm \& Fagan, 2008). Volunteering in the classroom could bring benefits for fathers through observed children learning the process at school and received advice from the teacher on how to participate in the children education (Fagan et al., 2016).

Whereas, in Indonesia, there is no specific program which targets fathers to engage themselves actively in classroom activities at the school, specifically in the early childhood education contexts, such as preschool and kindergarten. Despite that situation, there is a movement which is initiated by the Indonesian government to increase parental awareness of their presence in their children education. The initiation is called Sahabat Keluarga; in English term, this could 
be translated as "Family Friendly" program. Sahabat Keluarga is web-based program information established in 2015 which promotes and facilitates parents to become more aware of the importance of their presence at school and increase parents' awareness about their children education and learning developments in various levels of education, from preschool to high-school (Sahabat Keluarga, 2017). Most of the articles on the website provide different information, such as parenting programs, sharing knowledge and experience related to education among teachers and parents, updated news about the condition of school in Indonesia, and forum for parents and educators.

However, fathers' attitude towards participation in their children education could determine whether they are going to engage with their children education or not. According to, Palm and Fagan's (2008) study, the degree of their participation is influenced by their attitudes towards their involvement in early childhood program. Father who did not to value their involvement in their children activities and did not find any satisfaction in their interaction, would not see their involvement as their priority and would spend less time with their young children (Halme, Åstedt-Kurki, \& Tarkka, 2009). In other words, fathers who show less mutual interactions with their young children are related to negative attitudes towards their involvement (Halme et al., 2009).

Further, the family structure could be related to fathers' involvement (Halme et al., 2009). Halme et al. (2009) found that fathers who are divorced and fathers who are in non-traditional families tend to value the fathers-children interaction more compared to those in traditional families. However, talking about father itself could be defined differently in various context, as every family has different situations (Palm \& Fagan, 2008). The definition of a father could be explained as "biological connection, social connection, legal connection and psychological presence (Palm \& Fagan, 2008),p. 746). To illustrate, some families live separately with their fathers because the fathers need to work far from home; this situation could be known as nonresidential father (Palm \& Fagan, 2008). In other situation, it is possible that the presence of a father remains invisible because of the father's death or father divorce. Due to the various presence of a father in the family, I assume that fathers' involvement could be different in various context based on the condition of the family itself.

\subsection{The importance of fathers' involvement in early childhood education}

Empirical studies have revealed that participation of father in their children education give a positive input for both father and children (Anderson et al., 2014; Fagan et al., 2016). Fathers who are engaging themselves in various activities with their children are more aware that they are valued for their children (Anderson et al., 2014). Palm and Fagan (2008) stated that fathers who are helping their children to have a better academic performance in school feel that they are reducing a "father absence" issue in their community (p.754).

Parents are the "primary educator" who is responsible for providing information about religion, moral, and cultural education and for teaching their children informally about how to read, write and count. (Mathwasa \& Okeke, 2016a, p.229). Fathers' involvement from early ages has an essential role in positive outcomes towards cognitive development in children 
(Mathwasa \& Okeke, 2016a). Goldman (2005) stated that statistically, fathers' engagement in children learning is related to children's learning outcomes, better exam results, excellent academic performance at school, more higher chance to continue their studies in higher level of education, having more an optimistic attitude and good behaviour (as cited in Mathwasa \& Okeke, 2016a). Further, fathers' involvement is linked to children socio-emotional and better academic functioning at school (Mathwasa \& Okeke, 2016b).

Direct activity, such as reading at home could improve children language development (Fagan et al., 2016; Palm \& Fagan, 2008). The research findings from Fagan at al. (2016) shows there is a positive relation between children's language with fathers-children interaction, such as playing and reading at home in Head Start children. Reading children at home could enrich children vocabulary and introduce children to the new world, which are rarely used in daily life (Fagan et al., 2016). In Indonesia, there is a positive correlation between fathers-children relation and learning abilities of young children, which is found in Fathonah and Abidin's (2016) study. Children who have close relationships with their fathers tend to have better problemsolving skills and cognitive development (Fathonah \& Abidin, 2016).

Moreover, fathers' participation in children life also increases children well-being, happiness, lower risk of depression, and positive input for children social life (Fathonah \& Abidin, 2016). Thus, developing a healthy relationship with parents at school could give benefit toward teaching and learning (Mathwasa \& Okeke, 2016b). Mathwasa and Okeke (2016b) found that educators view fathers' involvement is father being present for their child is physically and emotionally ways and shows their interest in children's schoolwork. Strengthening fathers' participation in early childhood education can significantly reduce the need to invest in closing the gap between academic achievement and failure later in life (Karoly et al. 2005; Barnett and Belfield 2006, as cited in Mathwasa \& Okeke, 2016b).

\subsection{The challenges of fathers' involvement in early childhood education}

Despite talking about all the important factors of fathers' involvement in early childhood education, there is some condition which could limit fathers' participation in their children education. There are various factors which could affect fathers' presence in children education activities, including culture, income, working hours, and socioeconomic backgrounds (Bauman \& Wasserman, 2010; Fathonah \& Abidin, 2016; Ihmeideh, 2014).

Other study also found that there are some barriers which fathers face to getting more involve in their children education, such as teachers' and mothers' attitude toward fathers' participation, social beliefs regarding male involvement in child care, family's stereotypes, father's education, lack of time due to non-regular work schedule, lack of knowledge of father to getting participate themselves in their children activities, and absent father syndrome (Mathwasa \& Okeke, 2016a). Socio-cultural and tradition are also limit father to getting more involved in their children education (Palm \& Fagan, 2008).

The research discovered that mothers have crucial factors in assisting the relationship between father and children at home (Palm \& Fagan, 2008). Furthermore, teacher attitudes towards 
fathers are often limit fathers to participate in their children activity at school actively. (Mathwasa \& Okeke, 2016a). Based on Mathsawa \& Okeke (2016b) studies, teachers are rarely inviting fathers into their classroom activity. Although teachers are aware that father may have a significant impact on their children education, teachers have not directly asked them to engage in their children education at school (Mathwasa \& Okeke, 2016b).

Similarly, based on author experience as a teacher assistant in the local kindergarten, the school are aware that involving the fathers in activity at school would give a good insight for both of children and fathers. However, lack of knowledge of the teacher to how to engage more fathers to participate in school activity limit father in participating in the annual meeting program at school. The Head of school initiates to involve the father in school annual activity which is inviting all family member to join in "School Days' Out", a program which enables all family members to go out together to the particular place. This activity intends to strengthen the relationship between school and family, teacher and family, and among families at school. This condition is also in accordance with Warin's (2012) field notes, which were gathering information from a kindergarten in Indonesia shows that mothers' presence at school was higher than that of fathers'. To illustrate, almost every occasion at school, only mothers who attend the meeting, for instance, during the school's performance, the participants were dominated by mothers (Adriany \& Warin, 2012).

Furthermore, the school did not have specific programs which aim to enable fathers to become actively involved in their children education at school. The School Day's Out program is not a program which specifically invites fathers to participate; it is family gathering held by the school committee. However, from that phenomenon, it is found that fathers' participation in the School Days' Out program is higher than the school-parent meeting program. This condition could be described by the interest of fathers in engaging themselves in their children school program are higher while the program is inviting all family members (Palm \& Fagan, 2008). Thus, the fathers' participation in this program was influenced by various reasons, such as the economic condition of family and father's time limitation because they need to go to the workplace. Fathers perceive themselves as family resources where the responsibility to provided family needed are relied on their shoulder (McBride et al., 2017).

According to previous studies, it is found that the dominance of female staff in early childhood area, such as child care and kindergarten becoming one of the challenges that educator face to engage father participation in their children education (Ihmeideh, 2014). Early childhood education setting is dominant with female teachers who are the environment is more feminine, this condition might affect fathers' presence in children education activities (Ihmeideh, 2014; Palm \& Fagan, 2008). The dominance of female staff at childcare area, such as kindergarten makes fathers feel a little bit shy to getting participate in a school activity. The fathers feel that they are not confident to engage in the classroom activities, and they feel more confidence to participate if the mothers accompany them in the activities (Palm \& Fagan, 2008). Referring to Mathwasa \& Okeke study (2016b), the domination of female in this area known as 'womanto-woman' or 'mother-to-mother' syndrome, which refer to leaving fathers behind in participation at children school (p. 176). 
Further, there is a specific case in South Africa; the barriers of fathers' involvement in childhood education is linked to children paternity information (Mathwasa \& Okeke, 2016a). This means that the father still doubts of the children presents itself, are the child is their biological children or not. For them, this condition is a matter. This situation is remaining difficult for educators at school to involve the father in childhood education because the presence of the father is still questioned among family member. Besides, because of parents' literacy level, fathers feel less confident to participate in their children school activity (Mathwasa \& Okeke, 2016b).

\subsection{Implication of fathers' involvement in early childhood education}

A number of studies have revealed many positive correlations between fathers' participation and children learning ability (Anderson et al., 2014; Bauman \& Wasserman, 2010; Fathonah \& Abidin, 2016; Mathwasa \& Okeke, 2016a, 2016b). However, several studies also discovered the challenges of fathers' involvement in their children education, which could be narrowed to the fathers' background and the dominance of female staff at early childhood education context. To address the challenges of fathers' participation, Mathwasa and Okeke's (2016a) claims that participation of fathers at school activities depends on teachers' ability and willingness to perceive the father's presence. Consequently, school, as the institution need to have sufficient strategies to engage fathers in their children education at school activities. Communication between school and parents becomes an essential factor in establishing positive relationships between the two parties. It is essential for educators to initiate the invitation for fathers to ask them to actively participate in the school (Mathwasa \& Okeke, 2016b). Mentioning fathers at the invitation would give the father encouragement to getting participate in their children activities at school. Furthermore, school as a provider could initiate a program which is customised to engage fathers in school activities. Additionally, training for educators to have a certain skill to engage the fathers to gain their interest in participating in their children is also needed (Mathwasa \& Okeke, 2016b).

In addition, it is worth to take into account considered mothers attituded towards fathers' involvement in their children education as an essential variable. Fathers need to be endorsed by all adults, including mothers and teacher, to become more engaging themselves in their children education (Palm \& Fagan, 2008). Mothers support could encourage the father to involve themselves in the various interaction with their children (Palm \& Fagan, 2008). Based on this condition, providing an activity for all family members and inviting both mother and father, also could be considered as strategies by the school as a provider.

\section{Conclusion}

In conclusion, studies found that fathers with young children have a positive attitude towards their children's education. Research has concluded that the involvement of the father in young children education could give positive input for both father and children development. Interaction between father and children have positive relation towards children cognitive development, such as increasing literacy skills and better school outcome. 
Awareness of involving a father in a children education has been rising in Indonesia. Nonetheless, in Indonesia, fathers' participation in young children education remains low rather than mothers' involvement at school. In addition, there is a lack of program at schools which is focusing on fathers' participation at school-based activities in Indonesia, especially in the early childhood education setting. However, the web-based program has been initiated by the Indonesia government to engage more parents' participation in their children education and raise their awareness to be more involved in their young children education.

Further, there are various variable which determine father participation at school, including: values and norm in the society, family income, schedule of fathers' work, mothers' and teachers' attitude, and fathers' socioeconomic background (Bauman \& Wasserman, 2010; Fathonah \& Abidin, 2016; Ihmeideh, 2014; Palm \& Fagan, 2008). The domination of female presence in children education setting such as kindergarten and preschool are limiting fathers to participate in children education. To engage fathers to participate in children education, educator needs to have a good understanding of the background, cultures and unique strength of the children (Mathwasa \& Okeke, 2016a). The institution, as the education centres, can initiate high-quality collaborations with families and communities through community engagements (Mathwasa \& Okeke, 2016a).

\section{Acknowledgement}

The paper is fully funded by Indonesia Endowment Fund for Education (Lembaga Pengelola Dana Pendidikan/LPDP), Ministry of Finance Republic of Indonesia.

\section{References list}

Adriany, V., \& Warin, J. (2012). Gender power relations within the school's space and time: An ethnography study in an Indonesia Kindergarten. Paper presented at the Space, Place, and Social Justice in Education Conference.

Anderson, S., Aller, T. B., Piercy, K. W., \& Roggman, L. A. (2014). 'Helping us find our own selves': Exploring father-role construction and early childhood programme engagement. Early Child Development and Care, 185(3), 360-376. doi:10.1080/03004430.2014.924112

Bauman, D. C., \& Wasserman, K. B. (2010). Empowering fathers of disadvantaged preschoolers to take a more active role in preparing their children for literacy success at school. Early Childhood Education Journal, 37(5), 363-370. doi:10.1007/s10643009-0367-3

Fagan, J., Iglesias, A., \& Kaufman, R. (2016). Associations among head start fathers' involvement with their preschoolers and child language skills. Early Child Development and Care, 186(8), 1342-1356. doi:10.1080/03004430.2015.1094654

Fathonah, P. S., \& Abidin, Y. (2016). Studi kedekatan ayah dengan anak dan dampaknya bagi kemampuan belajar anak usia dini. Jurnal PGPAUD Kampus Cibiru, 4(2), 1-26.

Halme, N., Åstedt-Kurki, P., \& Tarkka, M.-T. (2009). Fathers' involvement with their preschool-age children: How fathers spend time with their children in different family structures. Paper presented at the Child Youth Care Forum. 
Ihmeideh, F. M. (2014). Giving fathers a voice: Towards father involvement in early years settings. Early Child Development and Care, 184(7), 1048-1062. doi:10.1080/03004430.2013.842562

Kementerian Pendidikan dan Kebudayaan Indonesia [Ministry of Education of Indonesia]. (2017). Sahabat Keluarga [Family Friendly]. Retrieved from http://sahabatkeluarga.kemdikbud.go.id/laman/index.php?r=tpost/xview\&id=39

Mathwasa, J., \& Okeke, C. (2016a). Barriers educators face in involving fathers in the education of their children in the foundation phase. J Soc Sci, 46(30), 229-240.

Mathwasa, J., \& Okeke, C. (2016b). Educators' perspectives on fathers' participation in the early childhood education of their children. International Journal of Educational Sciences, 13(2), 172-185.

McBride, B. A., Curtiss, S. J., Uchima, K., Laxman, D. J., Santos, R. M., Weglarz-Ward, J., . . . Kern, J. (2017). Father Involvement in Early Intervention: Exploring the Gap Between Service Providers' Perceptions and Practices. Journal of Early Intervention, 39(2), 71-87.

Palm, G., \& Fagan, J. (2008). Father involvement in early childhood programs: Review of the literature. Early Child Development and Care, 178(7-8), 745-759. doi:10.1080/03004430802352137

Rutgers WPF Indonesia. (2015). State of the world's fathers country report: Indonesia 2015. Retrieved from https://sowf.men-care.org/wp-content/uploads/sites/4/2015/06/SOWFCountry-Report-Indonesia-2015.pdf

Turbiville, V. P., \& Marquis, J. G. (2001). Father participation in early education programs. Topics in Early Childhood Special Education, 21(4), 223-231.

Yulindrasari, H., \& McGregor, K. (2011). Contemporary discourses of motherhood and fatherhood in ayahbunda, a middle-class Indonesian parenting magazine. Marriage \& Family Review, 47(8), 605-624. doi:10.1080/01494929.2011.619304 